\title{
ЭКСПРЕССИЯ ЦИРКУЛИРУЮЩИХ МИКРОРНК У ПАЦИЕНТОВ С АКРОМЕГАЛИЕЙ
}

Луценко А.С., Белая Ж.Е., Никитин А.Г., Лапшина А.М., Кошкин Ф.А., Солодовников А.Г., Рожинская Л.Я., Мельниченко Г.А., Дедов И.И.

ФГБУ «НМИЦ эндокринологии» Минздрава России, Москва

ЦЕЛЬ: определить циркулирующие микроРНК плазмы, специфические для акромегалии и оценить возможности их клинического применения.

МАТЕРИАЛЫ И МЕТОДЫ: исследование проведено в два этапа. На первом этапе проведен анализ экспрессии микроРНК методом высокопроизводительного секвенирования (NGS), на втором этапе микроРHK, выявленные на этапе NGS, валидизировались на расширенной выборке методом RT-qPCR, проведен корреляционный анализ с лабораторными, инструментальными и морфологическими данными пациентов.

РЕЗУЛЬТАТЫ: в первой части исследования выявлены три микроРНК-кандидата для дальнейшей валидизации: miR-4446-3p -1,317 ( $p=0,001)$, miR-215-5p -3,040 ( $p=0,005)$, miR-342-5p-1,875 ( $p=0,013)$. При анализе экспрессии на расширенной выборке пациентов с акромегалией $(n=47)$ по сравнению со здоровыми добровольцами ( $\mathrm{n}=28)$ методом RT-qPCR, подтверждены различия по двум микроРHK: miR-4446-3p $(p<0,001, p$ с поправкой<0,001), и miR-215-5p ( $<<0,001$, p с поправкой $<0,001)$. Площадь под ROC-кривой составила 0.864 (95\% ДИ 0.765-0.964) для miR-4446-3p ( $\mathrm{p}<0.001)$ и 0.833 (95\% ДИ 0,735-0,932) для miR-215-5p ( $<<0,001)$. Выявлены обратные корреляции между miR-4446-3p и ИФР1 ( $\tau=-0,35, p<0,001)$, miR-215-5p и ИФР1 ( $\tau=-0,31, p<0,001)$, прямые корреляции между miR-4446-3p и miR-215-5p ( $\tau=0,24, p<0,01)$, miR-210-3p и miR-146a-5p ( $\tau=0,28, p<0,05)$.

ВЫводЫ: в двухэтапном исследовании обнаружено и подтверждено снижение экспрессии miR-4446$3 p$ и miR-215-5p у пациентов с акромегалией по сравнению со здоровыми добровольцами. Данные микроРНК могут рассматриваться как потенциальные биомаркеры при акромегалии для дальнейших исследований. 